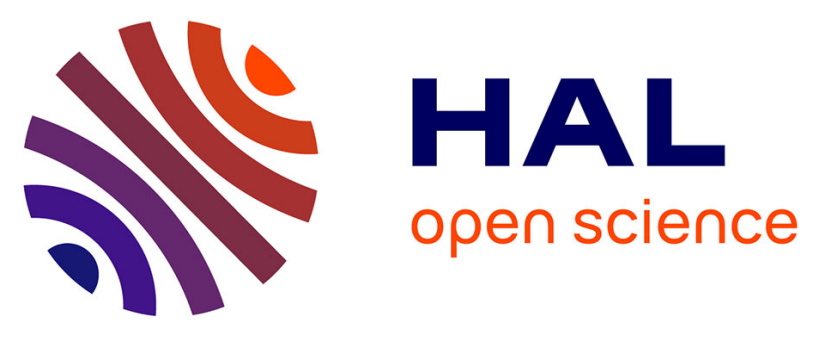

\title{
Numerical and experimental validation of transient modelling for Scramjet active cooling with supercritical endothermic fuel
}

Nicolas Gascoin, Philippe Gillard, Stephane Bernard, Marc Bouchez, Emeric Daniau, Emmanuel Dufour, Youssoufi Touré

\section{To cite this version:}

Nicolas Gascoin, Philippe Gillard, Stephane Bernard, Marc Bouchez, Emeric Daniau, et al.. Numerical and experimental validation of transient modelling for Scramjet active cooling with supercritical endothermic fuel. Collection of Technical Papers - 4th International Energy Conversion Engineering Conference, 2006, 1, pp.298-308. hal-00641635

\section{HAL Id: hal-00641635 \\ https://hal.science/hal-00641635}

Submitted on 17 Nov 2011

HAL is a multi-disciplinary open access archive for the deposit and dissemination of scientific research documents, whether they are published or not. The documents may come from teaching and research institutions in France or abroad, or from public or private research centers.
L'archive ouverte pluridisciplinaire HAL, est destinée au dépôt et à la diffusion de documents scientifiques de niveau recherche, publiés ou non, émanant des établissements d'enseignement et de recherche français ou étrangers, des laboratoires publics ou privés. 


\title{
Numerical and experimental validation of transient modelling for Scramjet active cooling with supercritical endothermic fuel
}

\author{
Nicolas GASCOIN*, Philippe GILLARD ${ }^{\dagger}$, Stéphane BERNARD \\ Laboratoire Energétique Explosion Structure, 63 avenue de Lattre de Tassigny, 18020 Bourges, France \\ Marc BOUCHEZ ${ }^{\S}$, Emeric DANIAU ${ }^{\mathbb{I l}}$, Emmanuel DUFOUR ${ }^{\#}$ \\ MBDA-France, 8 rue Le Brix, 18000 Bourges, France \\ and \\ Youssoufi TOURE** \\ Laboratoire Vision et Robotique, 63 avenue de Lattre de Tassigny, 18020 Bourges Cedex, France
}

\begin{abstract}
One of the main issues of hypersonic flight is the thermal management of the overall vehicle and more specifically the cooling of the engine. In order to simulate the behaviour of a complete actively cooled scramjet, a one-dimensional transient numerical model has been developed with heat and mass transfer in a cooling channel for supercritical fuel under pyrolysis. This model is called RESPIRE (French acronym for Scramjet Cooling with Endothermic Fuel, Transient Reactor Programming). A supplementary step by step validation of the model, based on 2-D numerical data from CFD-ACE, is presented in this paper. On stationary cases, fluid temperature profiles are in good agreement and values are comprised between those of centre fluid and those of near-wall fluid. Effects of one-dimensional semi-empirical correlations are shown and the boundary layer impact at the channel entrance is of great importance on wall temperatures. Heat fluxes conservation is verified and hydraulic behaviour too. On transient cases, temperature and velocity evolutions are well followed. Values after the change in mass flow rate are exactly those of stationary test case. RESPIRE is quantitatively validated under stationary and transient conditions and can be used to compare with experimental data. Qualitatively good agreement is found with experimental results on a chemical aspect.
\end{abstract}

$\begin{array}{ll}\text { A } & \text { Surface }\left(\mathrm{m}^{2}\right) \\ C_{f} & \text { Friction coefficient }() \\ D_{H} & \text { Hydraulic diameter }(\mathrm{m}) \\ \text { ee } & \text { length between two pin fins }(\mathrm{m}) \\ \mathrm{h} & \text { Convective heat transfer coefficient }\left(\mathrm{W} \cdot \mathrm{m}^{-2} \cdot \mathrm{K}^{-1}\right) \\ h_{c a n} & \text { Height of the channel }(\mathrm{m}) \\ \dot{m} & \text { Mass flow rate }\left(\mathrm{kg} \cdot \mathrm{s}^{-1}\right)\end{array}$

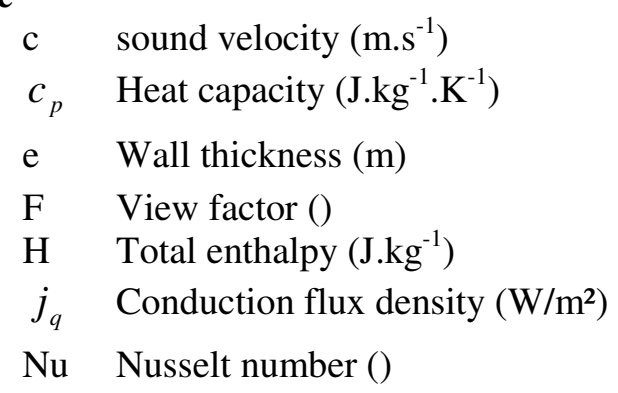

\footnotetext{
*PhD, Nicolas.Gascoin@ bourges.univ-orleans.fr.

${ }^{\dagger}$ University Professor, Philippe.Gillard@ bourges.univ-orleans.fr.

* University Doctor, Stephane.Bernard@ bourges.univ-orleans.fr.

$\S$ Aerospace engineer, marc.bouchez@mbda.fr, AIAA Member.

II Aerospace doctor, emeric.daniau@ mbda.fr, AIAA Member.

\# Aerospace engineer, emmanuel.dufour@mbda.fr, AIAA Member.

** University Professor, Youssoufi.Toure@bourges.univ-orleans.fr.
} 


$\begin{array}{ll}\mathrm{P} & \text { Pressure (Pa) } \\ \bar{T} & \text { Average temperature (K) } \\ \mathrm{t} & \text { Time (s) } \\ \mathrm{Y} & \text { Mass fractions () } \\ \mathrm{Z} & \text { Compressibility factor }() \\ Z_{c} & \text { Critical compressibility factor }() \\ \text { Greek } & \text { Letters } \\ \beta & \text { Thermal expansion coefficient }() \\ \beta_{c} & \text { Thermal compressibility coefficient }() \\ \varepsilon & \text { Emissivity }() \\ \kappa & \left.\text { Wall permeability (m }{ }^{2}\right) \\ \lambda & \text { Thermal conductivity }\left(\mathrm{W} \cdot \mathrm{m}^{-1} \cdot \mathrm{K}^{-1}\right) \\ \mu & \text { Dynamic viscosity (Pa.s) } \\ \rho & \left.\text { Density (kg/m }{ }^{3}\right) \\ \sigma & \text { Stefan-Boltzman constant }\left(W \cdot m^{-2} \cdot K^{-4}\right) \\ \tau & \left.\text { Friction tensor (Pa.m }{ }^{-1}\right) \\ \omega & \text { Pitzer acentric factor }() \\ \omega_{i} & \text { Net production rate of } \operatorname{species~} \mathrm{i}()\end{array}$

$\begin{array}{ll}\mathrm{r} & \text { Gases constant }\left(\mathrm{J} / \mathrm{kg}^{-1} \cdot \mathrm{K}^{-1}\right) \\ T & \text { Temperature }(\mathrm{K}) \\ V & \text { Velocity }\left(\mathrm{m}^{-1}\right) \\ \mathrm{x} & \text { Abscissa along the channel (m) } \\ \text { Subscripts } \\ 0 & \text { Standard conditions at } 298 \mathrm{~K} \\ \mathrm{CC} & \text { Combustion Chamber } \\ \mathrm{cw} & \text { cold face (of the porous wall) } \\ \text { ef } & \text { external face } \\ \text { ew } & \text { external wall } \\ & \text { ext external environment } \\ \mathrm{f} & \text { fluid } \\ \text { fm } & \text { film } \\ \text { hw } & \text { hot face (of the porous wall) } \\ \mathrm{i} & \text { species } \\ \text { if } & \text { internal face } \\ \text { pw } & \text { porous wall } \\ \text { s } & \text { static } \\ \text { y } & \text { Orthogonal direction to x abscissa }\end{array}$

\section{Introduction}

$\mathrm{H}$ YPERSONIC flight is expected to be achieved with dual-mode-Ramjet (Ramjet under Mach 6 and Scramjet beyond) ${ }^{1}$ because of its high specific impulse and its capability to be reusable (especially interesting for space transportation). Different cooling strategies have been evaluated by MBDA-France (calculations, material tests) ${ }^{2}$. Because even composite materials could not withstand such large heat load (the total temperature of external air reaches $4950 \mathrm{~K}$ at Mach 12), an active cooling system has to be used but not a dedicated one in order not to increase the vehicle weight. Furthermore ${ }^{3}$, the time allocated to mix the injected fuel with incoming air, to ignite the combustion and to complete it before the chamber outlet is about $1 \mathrm{~ms}$. These two points lead to use the fuel to cool down the engine's wall and then to burn it in the combustion chamber (CC). The liquid fuel is injected in a composite channel ${ }^{4}$ (which surrounds the engine) near the outlet of the $\mathrm{CC}$, it flows to the injection in an opposite way of the burned gases. A heavy hydrocarbon fuel is chosen here because of its high density compared to cryogenic fuels. When heated and pyrolysed, it produces lighter hydrocarbons species that are easier to ignite. This point allows responding to rapid phenomenon in the CC.

For such applications, some authors ${ }^{5,6}$ have programmed their own one-dimensional code or they have combined two codes. But they do not take into account the pyrolysis of the fluid nor its supercriticity or its effusion through porous wall. Due to the complex coupled phenomenon involved in the cooling channel, usual commercial software are not suitable for this purpose and a specific tool has to be developed.

The cooling system requires the control of the fuels decomposition, the cooling and secondly the combustion in the CC (to manage the thrust). It has to be noticed that due to the expected high pressure in the cooling loop ( $>3$ $\mathrm{MPa}$ ) the fluid becomes supercritical in the channel, which leads to some modelling difficulties (fluid properties and flow rate measurement) for the cooling study. The injected mass flow rate is expected to be slightly lower than the one pumped from the tank because of porous wall (film cooling appears on the CC side of the wall) and carbon deposit (coke, appearing from temperature higher than $900 \mathrm{~K}$ ). This phenomenon will also change the carbon/hydrogen ratio of the fuel in the channel. This point needs to be studied because it influences the combustion and $a$ priori the thrust.

Calculations of fluid properties have been presented and validated in previous work for viscosity, thermal conductivity $^{7}$ and heat capacity, density ${ }^{8}$. Transient conduction has been investigated in Ref. 9 using stationary and transient heat flux conditions. Less than $2 \%$ of variation on wall temperature, compared to analytical data, has been found with stationary heat flux. The transient heat flux shows a slight time shift of wall temperature, probably because of the use of average wall temperature to determine the two faces temperatures. Calculation method of fluid composition has been studied in Ref. 8,9 under stationary conditions. Compared to an experimental test with 
NORPAR-12, the n-dodecane pyrolysis gives relatively good agreement (typically $3 \%$ variations on mole fractions). Further validations on fluid temperature have been briefly approached in Ref. 9 .

The purpose of this present work (within the framework of the COMPARER project, french acronym for COntrol and Measure of PArameters in a REacting stReam) is firstly to give governing equations of heat and mass transfer in a heated channel fuelled with reacting endothermic fuel flow, potentially supercritical. The modelling is called RESPIRE (French acronym for Scramjet Cooling with Endothermic Fuel, Transient Reactor Programming). Secondly, the in deep validation proposed here provides thermal and hydraulic data compared to numerical results (obtained with the commercial software CFD-ACE ${ }^{10}$ ) with good agreement and differences are understood and explained. This comparison has the prior advantage to determine how each part of the engine is taken into account; programming bugs are easier to found. Contrary to the earlier validation with various experimental test cases -not always exactly suitable for the model-, choosing numerical cases allows determining the influence of various parameters on final results. This way is the only one for this study in terms of hydraulic and transient behaviour because no experimental data about flow velocity and fluid temperature are available in time for different test cases. Experimental data coming from COMPARER test bench are suitable for validation because it has been specifically designed for this aim.

\section{Governing equations of the full transient model}

The main equations resolved by RESPIRE are presented in the following part. This code is based on knowledge acquired by MBDA-France, validated and used by stationary FORTRAN codes (for example NANCYNETIK ${ }^{7}$ ). The present code, programmed under MATLAB, integrates some parts with a transient and a more detailed approach.

\section{A. Geometry of the cooling channel and modelling assumptions}

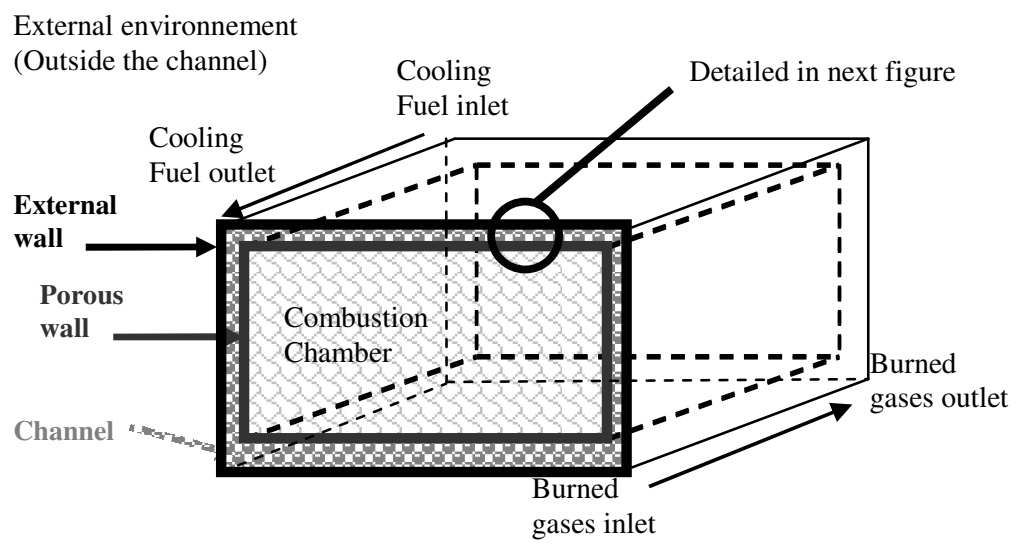

Figure 1. Generic representation of a cooled scramjet engine.

Figure 1 shows a scramjet engine considered with a rectangular section. The cooling channel is detailed on the Figure 2. Each wall (the external one and the porous one, which are linked by numerous pin fins) is in contact with different environment (outside the vessel and inside the combustion chamber). Because RESPIRE is a 1-D code, all variables are constant on a cross-section of the fluid or of the material. The fluid is considered to be homogeneous on each slice along the flow and it is treated as an average single phase flow but possibly multi-species.

Equations are written in transient state and the resolving method is a finite differences one. Partial derivative equations are discretized in space (centered explicit scheme) and then solved in time (explicit scheme). The spatial step is of the order of $5 \mathrm{~mm}$ and the time step is chosen in behalf of the flow velocity expected in the channel so as to keep a particle inside a given spatial step between two time steps.

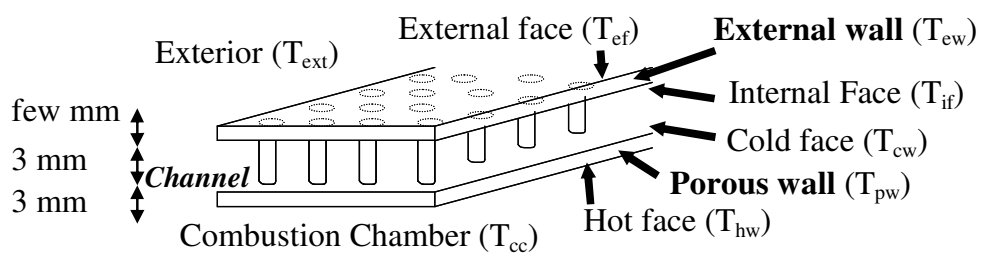

Figure 2. Identification of different cooling channels parts with interface between external environment and combustion chamber 
When use of the model is made for calculating the full engine, a flight configuration is chosen (altitude, velocity and vehicle's position), all geometrical data are defined (cross-section, length, width) and initial conditions, those of stationary case, are given. Boundary conditions are just the flight conditions (environment) because all needed variables are calculated inside the vehicle and engine. If the cooling channel is considered alone (without considering combustion phenomenon and vehicles flight conditions) in order to only calculate fuel pyrolysis and heat/mass transfers involved in the channel, additional boundary conditions have to be provided. Burned gases velocity/temperature/pressure are then given.

\section{B. Heat transfer in external and porous walls}

In this part, the external environment temperature is given whereas faces temperatures and wall temperature are calculated. The thermal gradients in walls are supposed to be linear (Biot number less than 0,1) to compute an average temperature in the wall $\bar{T}_{w}$ (considering radiative, convective and conductive heat fluxes) and then to deduce the two faces temperature of each wall. For example, equations 1 and 2 allow determining respectively $T_{e f}$ and $T_{i f}$ for the external wall $\left(\bar{T}_{e w}=\left(T_{e f}+T_{i f}\right) / 2\right)$. The same kind of expressions (equations 3 and 4 ) is used to compute temperatures in porous wall $\left(T_{h w}\right.$ and $T_{c w}$ with $\left.\bar{T}_{p w}=\left(T_{h w}+T_{c w}\right) / 2\right)$ but radiative heat transfers between walls are not considered inside the combustion chamber because of its squared geometry (each wall receives as energy as it emits). The radiative transfer from the gas to the walls is linearised (low discrepancies between walls and gas temperatures) and it is integrated in the convection coefficient. To write equations 1 and 2 , convection with the cooling fluid at the surface of the walls is considered to be equal to conduction into these walls.

$$
\begin{gathered}
\frac{\partial \bar{T}_{e w}}{\partial t}=\frac{1}{\rho_{e w} \cdot c_{p_{e w}} \times\left(e_{e w} \cdot A_{e w}\right)}\left(h_{e w-e x t} \cdot A_{e w} \cdot\left(T_{e x t}-T_{e f}\right)+\varepsilon \cdot \sigma \cdot A_{e w} \cdot F_{e w-e x t} \cdot\left(T_{s e x t}^{4}-T_{e f}^{4}\right)+\lambda_{e w} \cdot A_{e w}\left(\frac{T_{i f}-T_{e f}}{e_{e w}}\right)\right) \\
\frac{\partial \bar{T}_{e w}}{\partial t}=\frac{1}{\rho_{e w} \cdot c_{p e w} \times\left(e_{e w} \cdot A_{e w}\right)}\left(\lambda_{e w} \cdot A_{e w}\left(\frac{T_{e f}-T_{i f}}{e_{e w}}\right)-h_{f-i f} \cdot A_{e w} \cdot\left(T_{i f}-T_{f}\right)\right) \\
\frac{\partial \bar{T}_{p w}}{\partial t}=\frac{1}{\rho_{p w} \cdot c_{p_{p w}} \times\left(e_{p w} \cdot A_{p w}\right)}\left(\lambda_{p w} \cdot A_{p w}\left(\frac{T_{h w}-T_{c w}}{e_{p w}}\right)-h_{f-c w} \cdot A_{p w} \cdot\left(T_{c w}-T_{f}\right)\right) \\
\frac{\partial \bar{T}_{p w}}{\partial t}=\frac{1}{\rho_{p w} \cdot c_{p_{p w}} \times\left(e_{p w} \cdot A_{p w}\right)}\left(h_{h w-c c} \cdot A_{p w} \cdot\left(T_{c c}-T_{h w}\right)+\lambda_{p w} \cdot A_{p w}\left(\frac{T_{c w}-T_{h w}}{e_{p w}}\right)\right)
\end{gathered}
$$

$h_{f-i f}$ is considered at the following film temperature: $T_{f m}=\left(T_{f}+T_{i f}\right) / 2$ and is given by: $h=\left(N u \times \lambda_{f m}\right) / D_{H}$ with $D_{H}=\left(2 \times e e \times h_{c a n}\right) /\left(e e+h_{c a n}\right)$ where turbulent semi-empirical formula are used for Reynolds number (Colebrook formula with pin fins), Prandtl number and Nusselt number (Colburn correlation with tube in quincunx).

\section{Equations for fluid flow inside the cooling channel}

In this part, $V_{f}$ is determined by the momentum equation (4) and $H_{f}$ by the energy equation (5). In the momentum equation (4), the term $\partial\left(\rho_{f} . V_{f}\right) / \partial t$ can be written as: $\rho_{f} . \partial V_{f} / \partial t+V_{f} . \partial \rho_{f} / \partial t$. Consequently, continuity equation (3) is used to write: $\frac{\partial\left(\rho_{f} \cdot V_{f}\right)}{\partial t}=\rho_{f} \cdot \frac{\partial V_{f}}{\partial t}+V_{f} \cdot \frac{\partial \rho_{f}}{\partial t}=\rho_{f} \cdot \frac{\partial V_{f}}{\partial t}-V_{f} \cdot\left(\frac{\partial\left(\rho_{f} \cdot V_{f}\right)}{\partial x}\right)$. The fluid is considered to exchange with walls by convection only. Equations 3 to 5 are given without the effusion term through the porous wall because no validation has presently been conducted on this point. An equation of state $(P / \rho=Z . r . T)$ is used to determine density $\left(\rho_{f}\right)$ considering the compressibility factor: $Z=Z^{+(0)}+\omega . Z^{+(1)}$ with $\omega=\left(0,2901-Z_{c}\right) / 0,0879$ the Pitzer acentric factor. The Lee-Kesler tables ${ }^{11}$ are needed for $Z^{+(0)}, Z^{+(1)}$ and to correct the heat capacity on behalf of temperature and pressure. This approach is adapted to the pressure range and allows representing the supercritical part of the fluid flow inside the channel. Pressure of fluid is determined by use of Bulk Modulus $\beta=\partial P /(\partial \rho / \rho)$ with $\beta=\rho . c^{2}{ }^{12,13}$. Buoyancy is not taken into account because the Grashof number divided by the squared Reynolds number is lower than unity ( $G r / \operatorname{Re}^{2} \approx 0.3$ for a typical fluid flow inside the cooling channel) and because of the small dimension of the cooling channel (few millimetres, less than the boundary layer thickness). 


$$
\begin{gathered}
\frac{\partial\left(\rho_{f}\right)}{\partial t}+\frac{\partial\left(\rho_{f} \cdot V_{f}\right)}{\partial x}=0 \\
\frac{\partial\left(\rho_{f} \cdot V_{f}\right)}{\partial t}+\frac{\partial\left(\rho_{f} \cdot V_{f}^{2}\right)}{\partial x}=-\frac{\partial P_{s f}}{\partial x}+\frac{\partial \tau}{\partial x} \\
\frac{\partial\left(\rho_{f} \cdot H_{f}\right)}{\partial t}+\frac{\partial\left(\rho_{f} \cdot V_{f} \cdot H_{f}\right)}{\partial x}=\left(1-\beta_{c} \cdot T_{s f}\right) \frac{\partial P_{s f}}{\partial t}+\frac{\partial}{\partial x}\left(-j_{q}+V_{f} \cdot \tau\right)+\rho \cdot \sum_{\text {especes }} h_{i, 0} \cdot w_{i} \\
+\frac{1}{h_{c a n}} h_{c w}\left(T_{c w}-T_{f}\right)+\frac{1}{h_{c a n}} h_{i f}\left(T_{i f}-T_{f}\right)
\end{gathered}
$$

with $\frac{\partial \tau}{\partial x}=-\frac{C_{f}}{2} \times \rho_{f} . V_{f}^{2} \times \frac{p}{S}=-\frac{C_{f}}{2} \times \rho . V_{f}^{2} \times \frac{4}{D_{H}}$ and $j_{q}=-\lambda_{f} \cdot \operatorname{grad}\left(T_{f}\right)$

The thermal expansion coefficient is given by: $\beta_{c}=1 / \rho \times \partial \rho /\left.\partial T\right|_{P}{ }^{14,15}$ and the Darcy's law $\left(\dot{m}_{w}=\kappa \times \frac{\Delta P}{e_{w}} \times A_{w} \times \frac{\rho_{f y}}{\mu_{f y}}\right)$ is needed to take into account the loss of mass flow rate through porous wall of the combustion chamber (when applicable).

\section{Chemistry of pyrolysis and transport equation of compounds}

The transport equation (6) is solved for chemical species inside the cooling channel:

$$
\frac{\partial\left(\rho_{f} \cdot Y_{i}\right)}{\partial t}+\frac{\partial\left(\rho_{f} \cdot V_{f} \cdot Y_{i}\right)}{\partial x}=\rho_{f} w_{i}-\frac{1}{h_{c a n}} \rho_{f y} \cdot V_{f y} \cdot Y_{i}
$$

The mass fractions of compounds are calculated thanks to this species balance. The net production rates $\left(w_{i}\right)$ of species $i$ are determined using a complete validated pyrolysis mechanism for n-dodecane (1185 reactions and 153 species, designed by the french laboratory DCPR ${ }^{16}$ solved with a toolbox for MATLAB named CANTERA ${ }^{17}$, which is similar to the code CHEMKIN-II written in FORTRAN language. This accounts for temperature and pressure dependence of pyrolysis. Then, it can influence temperature fluid because of endothermic effects.

\section{E. Physical properties of fluid}

Details of the following part can be found in Ref.18. Dynamic viscosity and thermal conductivity are computed using the Guo et al. method ${ }^{19}$, which takes into account the fluid composition, the pressure and the temperature (and so supercritical fluid specificity). CHEMKIN polynomials are used to calculate the heat capacity, which is then corrected thanks to the Lee-Kesler tables. More details are provided in Ref. 11.

\section{Validation test cases}

Multiple validations have already been conducted with various experimental, analytical and numerical data (see Ref.18 for more details). Two of the most recent validation cases are presented here: on a numerical point of view (with CFD-ACE software) and on an experimental point of view (with the COMPARER test bench). Velocities of fluid flow inside the cooling channel are expected to be subsonic (a few tens of $\mathrm{m} \cdot \mathrm{s}^{-1}$ ). Because of the low mass flow rate available on the COMPARER test bench, velocities for the present validation cases are less than one $\mathrm{m} . \mathrm{s}^{-1}$.

\section{A. Numerical data}

RESPIRE is only used with the cooling channel and not with the complete vehicle (no such cooled engine exists presently and no adapted software are suitable for validations). Three test cases are presented, two stationary and one transient. The geometric configuration (Figure 3) under study is a two dimensional channel $\left(\mathrm{L}=1 \mathrm{~m} ; \mathrm{e}_{1}=\mathrm{e}_{2}=\right.$ $\mathrm{e}_{3}=3 \mathrm{~mm}$ ) composed of two parallel walls. The fluid flowing between the two walls has a mass flow rate of $0,1 \mathrm{~g} / \mathrm{s}$ for the first stationary test case and $0,05 \mathrm{~g} / \mathrm{s}$ for the second one. The transient one starts with $0,1 \mathrm{~g} / \mathrm{s}$ and change suddenly to $0,05 \mathrm{~g} / \mathrm{s}$. The fluid temperature at the entrance of the channel is always fixed at $600 \mathrm{~K}$ and the pressure (fixed at 35 bars) can be assumed at the entrance (RESPIRE) or the exit (CFD-ACE) of the channel because of the almost negligible pressure loss. The outside surfaces of the channel are maintained at $1400 \mathrm{~K}$ (isothermal). In order to have simple test cases (discrepancies between codes are thus easier to analyse), fluid properties are fixed and given in Table 1 as the ones for solid walls. Pyrolysis chemistry is not taken into account. A space step for CFD$\mathrm{ACE}$ of $5 \mathrm{~mm}$ in the fluid direction is choose; the one in the orthogonal way is $0,1 \mathrm{~mm}$. 


\begin{tabular}{ccccc} 
& $\begin{array}{c}\text { Thermal conductivity } \\
\left(\mathrm{W} \cdot \mathrm{m}^{-1} \cdot \mathrm{K}^{-1}\right)\end{array}$ & $\begin{array}{c}\text { Heat capacity } \\
\left(\mathrm{J} \cdot \mathrm{kg}^{-1} \cdot \mathrm{K}^{-1}\right)\end{array}$ & Density $\left(\mathrm{kg} \cdot \mathrm{m}^{-1}\right)$ & $\begin{array}{c}\text { Dynamic viscosity } \\
(\text { Pa.s })\end{array}$ \\
\hline Solid & 30 & 1500 & 2000 & - \\
\hline Fluid & 0,0879 & 3342 & 475 & $106,8.10^{-6}$
\end{tabular}

Table 1. Fixed fluid and solid properties for validation test cases.

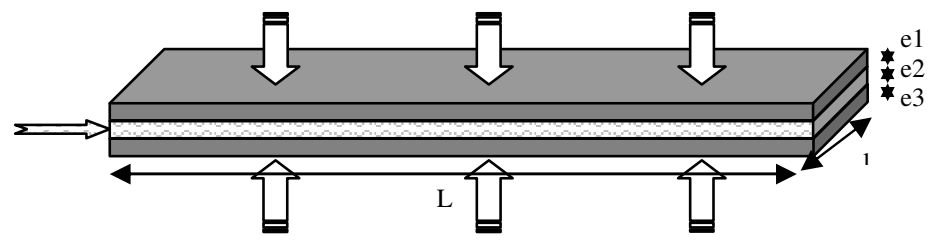

Figure 3. Schematic test case of fluid flow between two parallel walls.

\section{B. Experimental data}

A dedicated test bench for the COMPARER project has been designed for the n-dodecane pyrolysis under supercritical conditions (1900 K, 80 bars). The Figure 4 shows a schematic representation of the overall experimentation (Figure 5). The fuel (n-dodecane) is pumped out of the tank and injected at controlled pressure and mass flow rate into a continuous chemical reactor placed into the furnace. Depending on the fixed furnace temperature, pyrolysis products (received at ambient conditions inside the liquid/gas splitter) are separated and gas phase species are analysed by Gas Chromatograph (GC). Experimental data for code validation (mainly vapour, subcritical) have been obtained at different stable points in pressure and temperature for a given mass flow rate (Table 2). The maximum furnace temperature is approximately the maximum one for fluid because of high residence times (from $30 \mathrm{~s}$ to $80 \mathrm{~s}$ depending on the conditions). The mass gasification rate (in \%) is the mass of gas at the channel outlet (at ambient conditions) divided by the mass of injected fuel into the channel during the test.

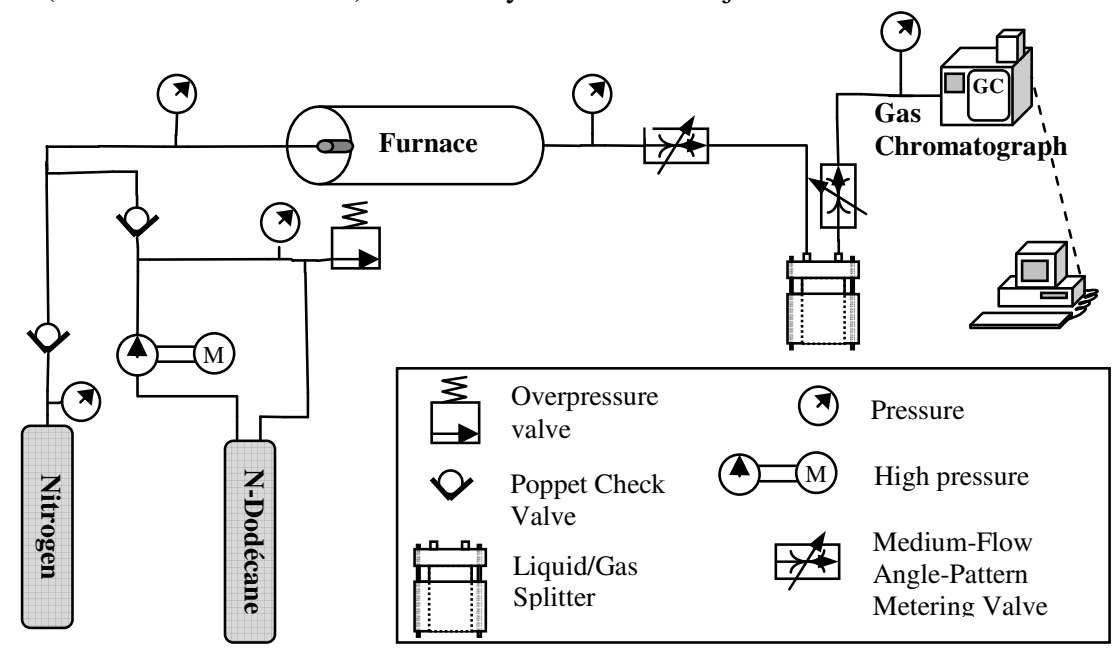

Figure 4. Schematic representation of the COMPARER bench for supercritical endothermic fuel pyrolysis.

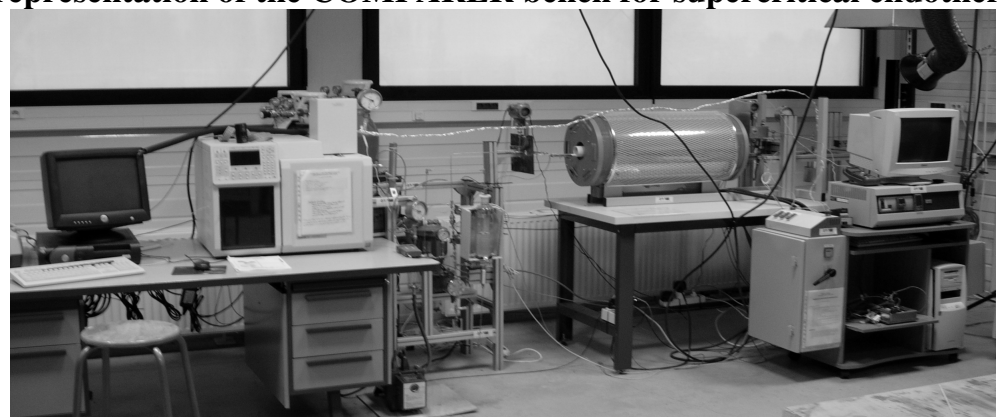

Figure 5. Experimental COMPARER bench for the test of measuring methods on pyrolysed hydrocarbon. 


\begin{tabular}{ccc}
\hline & Case 1 & Case 2 \\
\hline Maximum Furnace Temperature $\left({ }^{\circ} \mathrm{C}\right)$ & 770 & 825 \\
\hline Chemical reactor pressure (bars) & 12 & 10 \\
\hline Fuel mass flow rate $(\mathrm{g} / \mathrm{s})$ & 0.1 & 0.05 \\
\hline Molar fractions sum & 93,08 & 72,07 \\
\hline Conversion rate & $60 \%$ & $75 \%$ \\
\hline Mass Gasification rate & $17 \%$ & $100 \%$ \\
\hline $\mathrm{H} 2$ & 1,43 & $<, 01 \%$ \\
$\mathrm{CH} 4$ & 15,37 & 19,25 \\
$\mathrm{C} 2 \mathrm{H} 2$ & $<0,01 \%$ & $<0,01 \%$ \\
$\mathrm{C} 2 \mathrm{H} 4$ & 26,77 & 25,37 \\
$\mathrm{C} 2 \mathrm{H} 6$ & 15,39 & 11,27 \\
$\mathrm{C} 3 \mathrm{H} 6$ & 14,79 & 14,24 \\
$\mathrm{C} 3 \mathrm{H} 8$ & 5,65 & 1,94 \\
\hline
\end{tabular}

Table 2. Experimental data of gas analysis by GC for various stationary conditions. Mole fraction (\%) are measured at the reactor outlet.

\section{A. Stationary validation cases}

\section{Results and discussion}

Strong heterogeneities of fluid flow and thus heat transfer are shown through figures 6 to 8 by 2-D calculations (CFD-ACE). Because of the one-dimensional approach of RESPIRE, results need to be well understood.

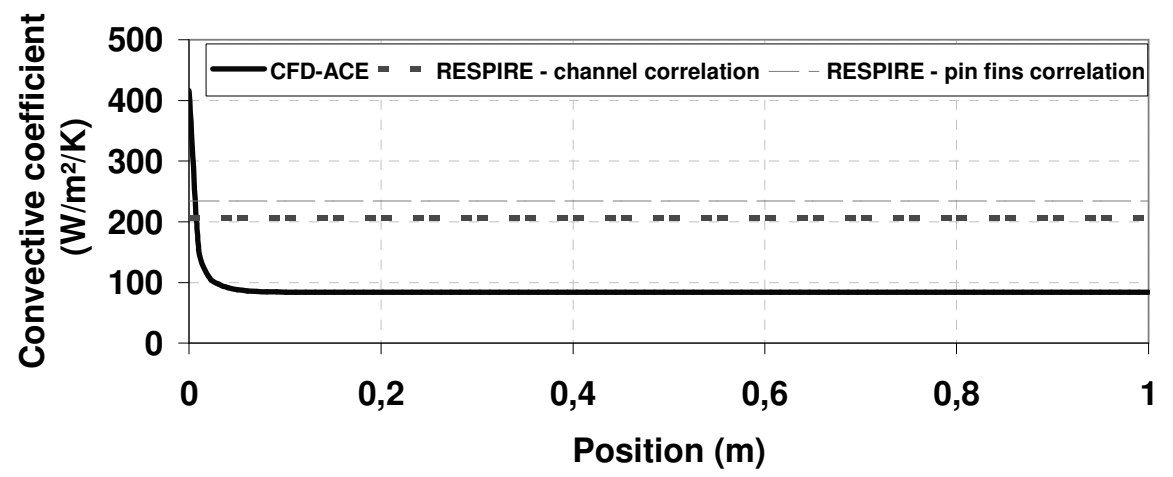

Figure 6. Discrepancies between convective coefficient calculation ways for the $0,1 \mathrm{~g} / \mathrm{s}$ stationary test case.

Into the present channel, a mass flow rate of $0,1 \mathrm{~g} / \mathrm{s}$ (respectively $0,05 \mathrm{~g} / \mathrm{s}$ ) corresponds to a fluid velocity of $8,772.10^{-3} \mathrm{~m} \cdot \mathrm{s}^{-1}\left(4,386 \cdot 10^{-3} \mathrm{~m} \cdot \mathrm{s}^{-1}\right)$. Residence times are about $114 \mathrm{~s}$ and $228 \mathrm{~s}$ for these two cases. The Reynolds number depends on the semi-empirical correlations used. Indeed, RESPIRE uses Colebrook formula with pin fins because the overall model has been designed for the vehicle, which cooling channel integrates such geometry (as shown in Figure 2). Whereas CFD-ACE uses semi-infinite 2-D channel (the hydraulic diameter $D_{H}=\frac{4 .\left(l \times e_{2}\right)}{\left(2 .\left(l+e_{2}\right)\right)} \underset{l \rightarrow \infty}{\longrightarrow} 2 . e_{2}=6.10^{-3} \mathrm{~m}$ gives a Reynolds number of 234 -respectively 117 for the second stationary case-), the pin fins geometry correspond to a Reynolds of 170 (respectively 85 ) $\left(D_{H}=4,36.10^{-3} \mathrm{~m}\right)$. Thus, the pressure losses are less than $15 \mathrm{~Pa}$. In the one-dimensional approach, a convective coefficient is considered between the fluid and the wall but it is not possible for CFD-ACE because it takes the boundary layer into account. To compare such a coefficient, the heat flux density between solid and fluid for CFD-ACE has been divided by the difference of wall temperature and near wall fluid temperature. The Figure 6 illustrates on the first stationary case the limitation of a 1-D model because it could not take into account a varying flow along the channel with some fixed parameters (fluid flowing from 0 to 1 meter, from left side to the right one). As density and mass flow rate are fixed, RESPIRE has a constant convective coefficient contrary to a 2-D approach. The influence of hydraulic diameter (calculation with pin fins and with channel correlation) and of convective coefficient (constant or varying along the channel) on wall temperature is clearly shown (Figure 7). It explains the discrepancies of temperature 
between the two compared models: less than $2 \%$ for wall temperatures and up to $15 \%$ for fluid temperature (Figure 8). The high differences in fluid temperature are due to the 1-D approach, which considers an average fluid temperature for each position along the channel whereas CFD-ACE takes a temperature profiles into account at each calculation node. The RESPIRE fluid temperature is comprised between the one at the centre of channel for CFD$\mathrm{ACE}$ and the one near the wall.

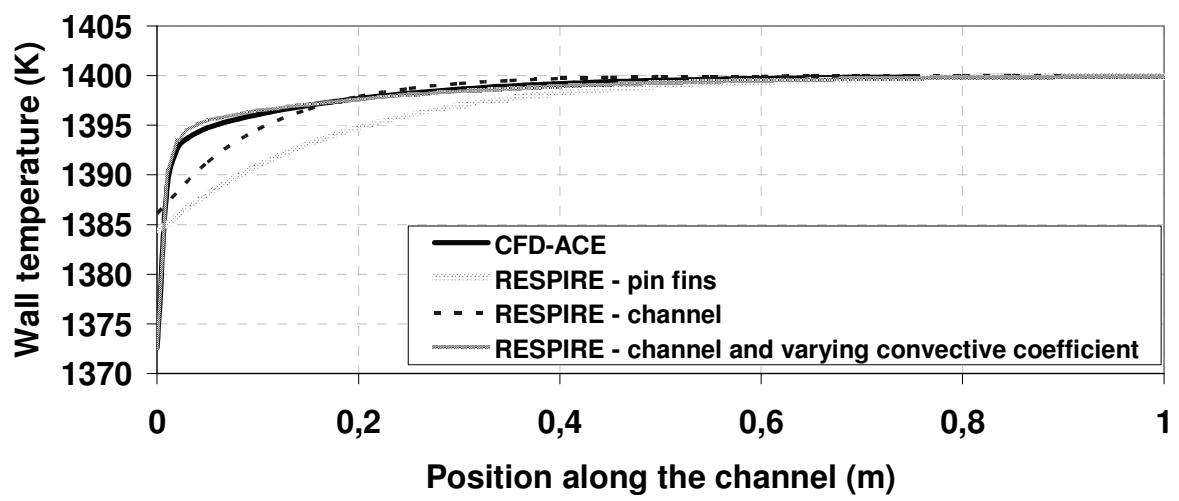

Figure 7. Temperature of wall in contact with fluid for CFD-ACE and RESPIRE (with pin fins or channel correlation and with convective coefficient values from CFD-ACE) for the $0,1 \mathrm{~g} / \mathrm{s}$ test case.

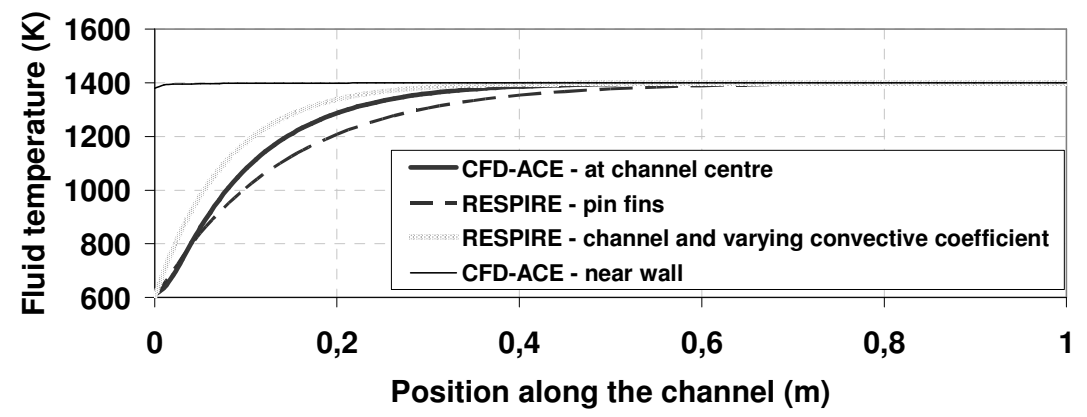

Figure 8. Fluid temperatures for CFD-ACE (centre of channel and near the wall) and for RESPIRE (with pin fins or channel correlation including convective coefficient from $2 \mathrm{D}$ data) for the $0,05 \mathrm{~g} / \mathrm{s}$ test case.

Another important point to study is the heat flux exchanged between the wall of the channel and the fluid. To heat the fluid from $600 \mathrm{~K}$ to $1400 \mathrm{~K}$, the necessary heat flux is $\Phi=\dot{m} \cdot C_{p} . \Delta T=267,36 W$ for the $0,1 \mathrm{~g} \cdot \mathrm{s}^{-1}$ test case (respectively $133,68 \mathrm{~W}$ for the other stationary case). It is possible under the transient model to compute the convective heat flux from the walls to the fluid: $\Phi(x)=h_{c w-f}(x) \cdot S_{c w, s t e p} .\left(T_{c w}(x)-T_{f}(x)\right)$ where $S_{c w, s t e p}$ is the convective surface of cold wall for one space step. Then, the total heat flux is the sum of fluxes on each cell and it is determined as: $\Phi=\sum_{i=1}^{\text {cell }} \Phi_{i}=\sum_{i=1}^{\text {cell }} \frac{\Phi\left(x_{i}\right)+\Phi\left(x_{i}+\Delta x\right)}{2}$. If CFD-ACE gives a heat flux of 133,8 W (for the second test case), RESPIRE gives a heat fluxes of $146 \mathrm{~W}$ for a space step of $50 \mathrm{~mm}$ (this value decreases to $142 \mathrm{~W}$ for $10 \mathrm{~mm}$ and $136 \mathrm{~W}$ for $1 \mathrm{~mm}$ ). This trend is just the result of the space step when calculating the heat flux because the higher the space step, the less suitable is the average between two points of calculations. The Figure 9 clearly shows that this point is only due to data post-treatment because values of fluid temperature are almost exactly the same, independently of space step. The residual differences for $1 \mathrm{~mm}$ (136 W versus 133,68 W) are due to approximated temperatures (one significant number) values used to compute this heat flux. 


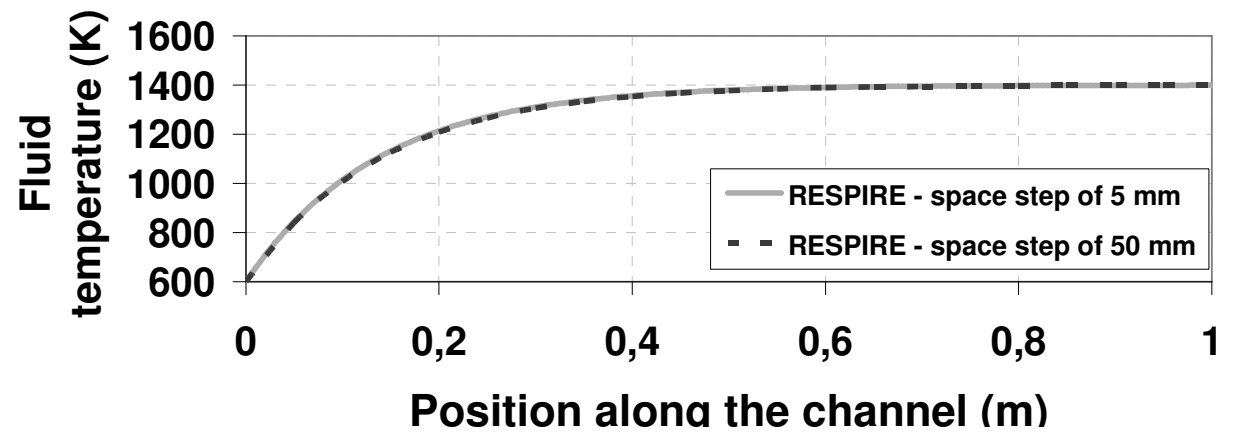

Figure 9. Fluid temperatures for CFD-ACE and the 1-D model (with and without fixed convective coefficient) for the $0,05 \mathrm{~g} / \mathrm{s}$ test case.

\section{B. Transient validation case}

The present case starts from the first stationary case conditions; after stabilisation, it changes suddenly to the second test mass flow rate and it computes until the equilibrium is reached. The full case is laminar (as the two preceding cases); the sudden flow rate change is assumed not to create turbulence. Because of long residence times, a time of $300 \mathrm{~s}$ is choose before and after the flow rate change to be sure to obtain stationary conditions. As equilibrium states of the transient case are exactly equal to the stationary ones, values are not presented here. The Figure 10 compares the RESPIRE data to the ones of CFD-ACE. Qualitative time evolutions are in good agreements and quantitative discrepancies at stationary conditions have already been explained. Temperature evolutions are comprised between stationary states; which was predictable. The time evolution for RESPIRE looks more linear than CFD-ACE because of the convective coefficient which is fixed for a given fluid velocity whereas for CFDACE, this coefficient varies along the channel. This gives a different fluid temperature evolution depending on the position into the channel.

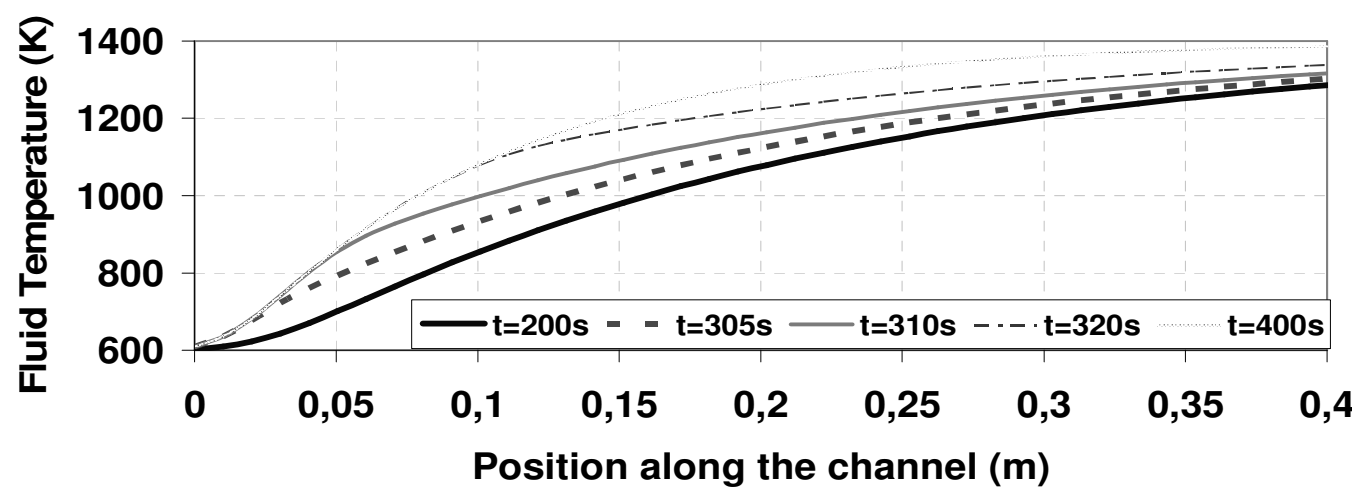

(a) CFD-ACE

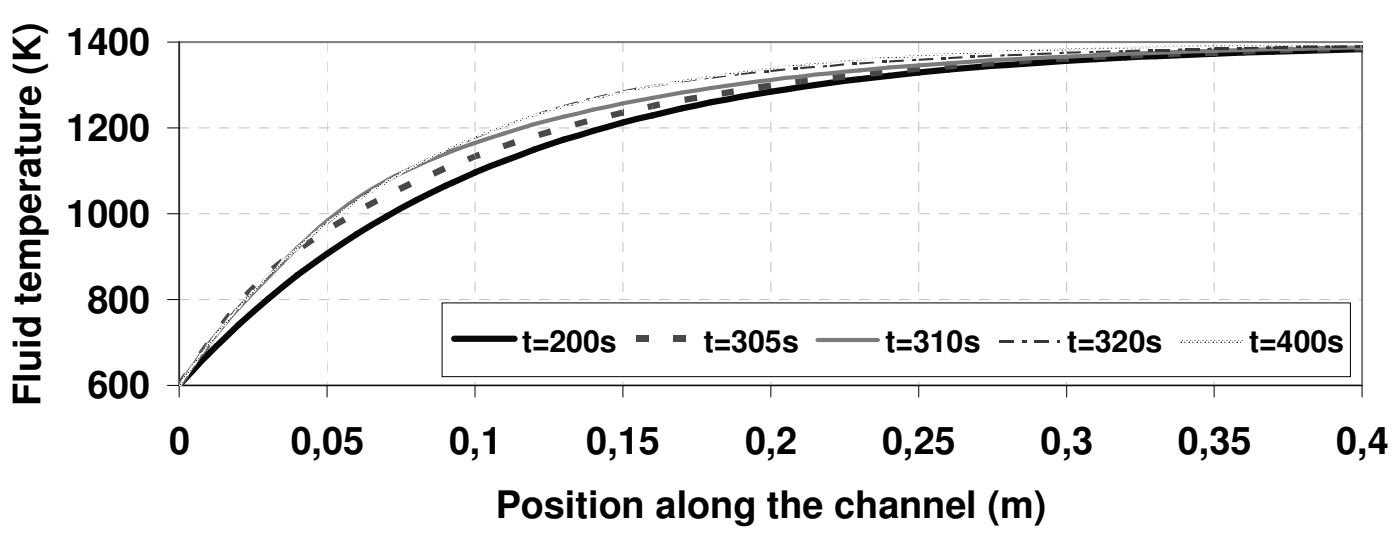

Figure 10. Fluid temperature evolution along the channel at different times for CFD-ACE (a) and RESPIRE (b). Mass flow rate $(0,1 \mathrm{~g} / \mathrm{s})$ divided by a factor 2 at a time of $300 \mathrm{~s}$.

(b) RESPIRE 
The evolution of velocity is of great interest. Because the fluid is treated in incompressible (density is constant), the sudden change in flow rate has for a consequence to divide by a factor 2 the velocity, instantaneously along the channel. This is given by writing the derivative of fluid mass in the whole channel (no accumulation term in incompressible flow):

$$
\frac{d m}{d t}=\frac{d(\rho . \mathrm{Vol})}{d t}=\dot{m}_{\text {inlet }}-\dot{m}_{\text {outlet }}
$$

where $\mathrm{Vol}$ is the volume of the channel. As the channel is not deformable: $\frac{d(\rho \cdot \mathrm{Vol})}{d t}=0$. The equation (7) is rewritten as: $\dot{m}_{\text {inlet }}-\dot{m}_{\text {outlet }}=\rho . S .\left.V\right|_{\text {inlet }}-\rho . S .\left.V\right|_{\text {outlet }}=\rho . S .\left(V_{\text {inlet }}-V_{\text {outlet }}\right)$. Consequently, the velocity at the entrance and at the exit of the channel is equal at each time step. This result is perfectly shown by the Figure 11.

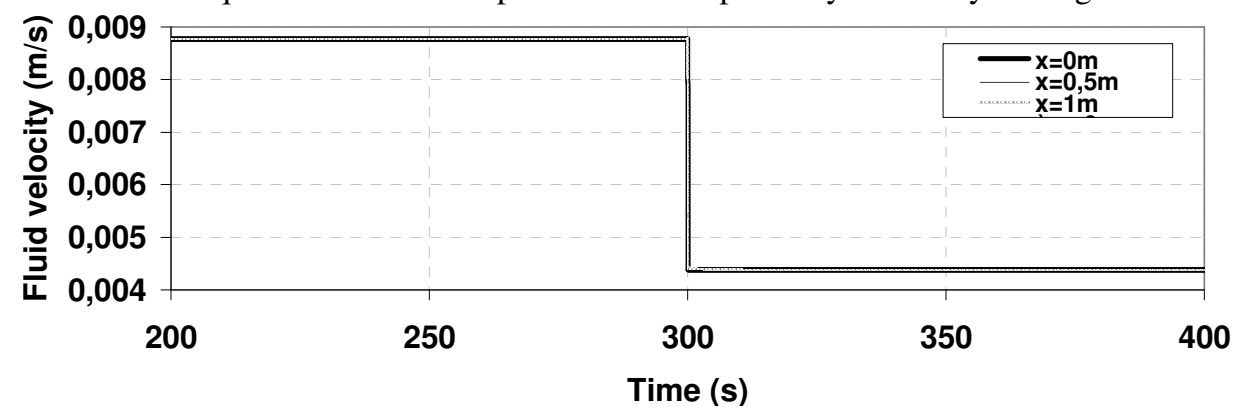

Figure 11. RESPIRE time evolution of fluid velocity in incompressible flow for a factor 2 division of mass flow rate at $300 \mathrm{~s}$; different positions along the channel.

\section{Chemical validation with experimental cases}

RESPIRE has been used to compute some experimental test cases run on the COMPARER test bench. The simple geometry of the bench allows easy numerical simulations. Inlet fluid temperature/pressure/flow rate and external wall surfaces temperatures are used as boundary conditions. Because only gas phase species at ambient conditions are studied (and only the ones given by Table 2 are quantified), only seven species are conserved (after finished calculations) and their molar fractions sum is made equal to the one of experimentally quantified species. Results are presented in Figure 12. Discrepancies are mainly due to the geometric configuration (pin fins are used in RESPIRE whereas a cylinder tube is experimentally used) and to the external wall temperature profile which is only supposed to be equal to the furnace temperature profile measured during the test. No other data (such as outlet fluid temperature of velocity) are available to compare RESPIRE to COMPARER data.
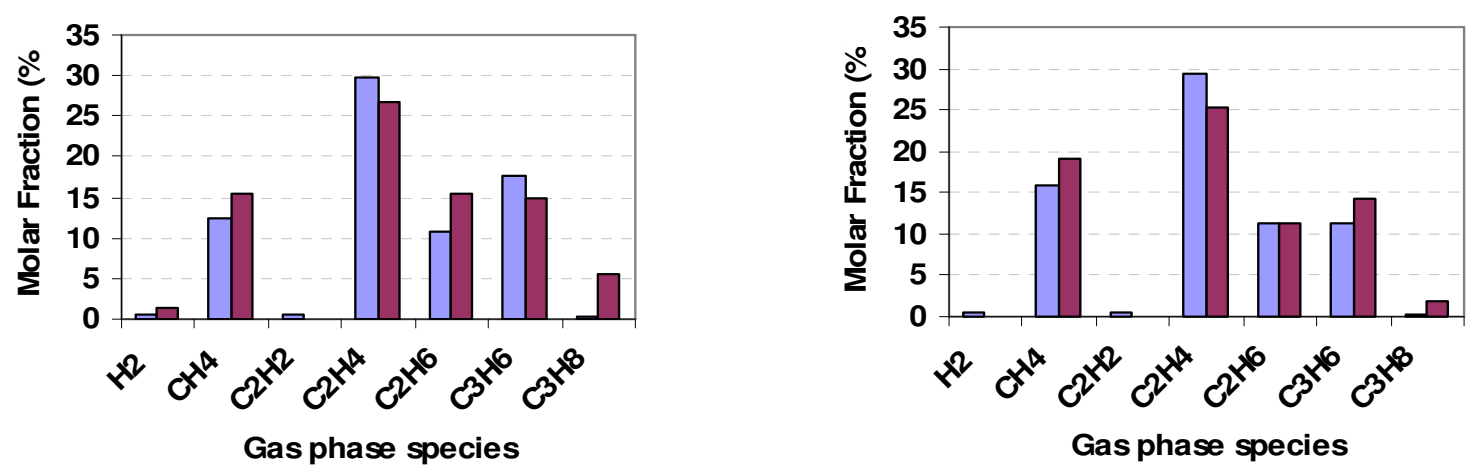

$\square$ Numerical data $\square$ Experimental data

$\square$ Numerical data $\square$ Experimental data

Figure 12. Chemical composition computed with RESPIRE for various experimental cases, comparison to experimental data.

\section{Conclusions}

For the COMPARER (french acronym for COntrol and Measure of PArameters in a REacting stReam) project, a one-dimensional transient model has been programmed in order to simulate the scramjet active cooling and to 
know the mixture composition at the cooling channel outlet. A complete detailed mechanism (1185 reactions and 153 species) has been used. Equations have been presented in this work and the main possible validations at this time (depending on the available data) have been conducted for most of the different identified parts. RESPIRE is quantitatively validated considering the one-dimensional modelling as differences to 2-D model are understood. Thermal and hydraulic time evolutions are satisfactory and quantitative results are acceptable for a 1-D model, used as pre-dimensioning tool. The stability of RESPIRE and its sensitivity to spatial step is ensured, as the convergence reliability. Through all the calculated cases, its adaptability to various configurations has been proved. To our knowledge, this is the first transient coupled model (thermal and mass transfers with chemical reactions under liquid, gas and supercritical conditions) for such a geometric configuration. Validation of RESPIRE should continue on phenomenon through the porous wall. This model should help to build a cooling strategy and to improve the dedicated experimental test bench, which can bring further validation data on a chemical aspect and on dynamical response of inlet time variations. It is hoped to use RESPIRE as a predicting and controlling tool for SCRAMJET cooling management. In this perspective, it could test measuring methods on the hydrocarbon fuel (like giving InfraRed spectroscopic data during calculations).

\section{Acknowledgement}

The authors would like to sincerely thank F. Falempin for his permanent support involving this project. The present work has been realised with the contribution of the "Conseil Général du Cher (18)", of the "Conseil Régional du Centre", of the FRED, of the FEDER, of the FSE and of MBDA-France. Their participation will make it possible to define and to evaluate, by means of calculation and of experimentation, one or two innovating technologies for the measurement of characteristic parameters of a heated hydrocarbon at high temperature (mass flow rate, specific chemical species). The good evolution of the COMPARER project was made possible thanks to the contribution of Y. Parmantier, person in charge of the project and coordinator of the "Pôle Capteurs et Automatismes" of Bourges.

\section{References}

F. Falempin, "High speed airbreathing propulsion: French activities", AIAA Paper 2002-5232, October 2002.

L. Boselli, T. Giraudo, A. Massot, B. Talbot, "Dual-fuel advanced high-speed ramjets", AIAA Paper 2002-5214, Oct. 2002.

Y.M. Shikhman, V.A. Vinogradov, L.S. Yanovski, V.A. Stepanov, V.E. Shlyakotin, S.N. Pen'kov, "The Demonstrator of Technologies - Dual Mode Scramjet on Hydrocarbon Endothermic Fuel", AIAA Paper 2001-1787, July 2001.

4 M. Bouchez, F. Falempin, G. Cahuzac, V. Avrashkov, "PTAH-SOCAR Fuel-Cooled Composite Materials Structure", AIAA Paper 2002-5135, October 2002.

5 Y. Nobuhiro, T. Kimura, T. Masahiro, O. Koichi, N. Hideyo, "Transient Analysis of the LE-7A Rocket Engine Using the Rocket Engine Dynamic Simulator (REDS)", AIAA Paper 2004-3850.

6 M.H. Naraghi, S. Dunn, D. Coats, "A Model for Design and Analysis of Regeneratively Cooled Rocket Engines", AIAA Paper 2004-3852.

7 E. Daniau, M. Bouchez, N. Gascoin, "Scramjet Active Cooling Analysis Using n-dodecane as a Generic Endothermic Fuel", Thermochemical Processes in Plasma Aerodynamics, St Petersburg, Russia, 12-14 July 2004.

$8 \quad$ N. Gascoin, P. Gillard, Y. Touré, S. Bernard, E. Daniau, M. Bouchez, "Mesures et contrôle de paramètres pertinents pour la régulation d'un statoréacteur mixte refroidi", Troisième Rencontre Capteurs, Bourges, France, 21 Octobre 2004.

$9 \quad$ N. Gascoin, P. Gillard, Y. Touré, S. Bernard, E. Daniau, M. Bouchez, "Modélisation hydraulique et thermique d'un fluide supercritique avec pyrolyse dans un canal chauffé: prédimensionnement d'une étude expérimentale", Congrès Français de Thermique, SFT 2005, Reims, France, 30 mai - 2 juin 2005.

10 E. Dufour, M. Bouchez, "Semi-empirical and CFD analysis of actively cooled dual-mode ramjets", AIAA Paper $2002-5126$.

11 J. Gosse, "Constantes thermodynamiques : données thermodynamiques des fluides", Techniques de l'Ingénieur, K535.

12 Daugherty R.L., Franzini J.B., Finnemore E.J., (1989) "Fluid Mechanics with Engineering Applications", Metric Editions.

13 Le Neindre B., "Effets des hautes et très hautes pressions", Techniques de l'Ingénieur, K484.

14 Bejan A., (2004) "Convection Heat Transfer", Third Edition, Wiley.

15 Bianchi A-M., Fautrelle Y., Etay J., (2004) "Transferts Thermiques", Presses Polytechniques et Universitaires Romandes.

16 K.D. Dahm, P.S. Virk, R. Bounaceur, F. Battin-Leclerc, P.M. Marquaire, R. Fournet, E. Daniau, M. Bouchez, "Experimental and modelling investigation of the thermal decomposition of n-dodecanee", J. Anal. Appl. Pyrol., 71, 2004, pp. 865-881.

17 D.G. Goodwin, "An Open-Source, Extensible Software Suite for CVD Process Simulation", Chemical Vapor Deposition XVI and EUROCVD 14, ECS Proceedings, Volume 08, The Electrochemical Society, 2003, pp. 155-162.

18 N. Gascoin, P. Gillard, Y. Touré, E. Daniau, S. Bernard, M. Bouchez, "Modélisation d'un statomixte refroidi par endocarburant supercritique : couplage thermique-chimie et transferts de matière", Récents Progrès en Génie des Procédés, $\mathrm{N}^{\circ} 92$, Ed. Lavoisier, 2005.

19 X.Q. Guo, C.Y. Sun, S.X. Rong, G.J. Chen, T.M. Guo, "Equation of State Analog Correlations for the Viscosity and Thermal Conductivity of Hydrocarbons and Reservoir Fluids", J. Petrol Sci Eng, 30, 2001, pp. 15-27. 